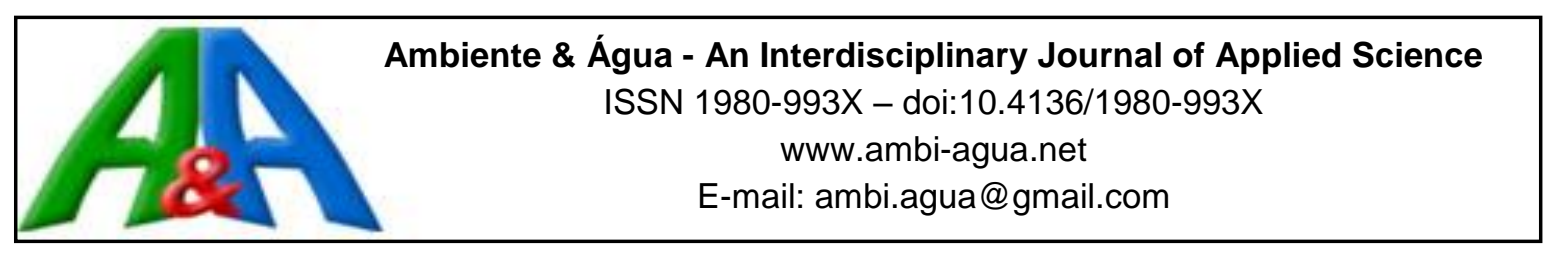

\title{
Aproveitamento de água de chuva de cobertura em edificações: dimensionamento do reservatório pelos métodos descritos na NBR 15527
}

\author{
doi:10.4136/ambi-agua.1940 \\ Received: 12 May 2016; Accepted: 27 Jul. 2017 \\ Jozrael Henriques Rezende*; Natália Tecedor \\ Faculdade de Tecnologia de Jahu (Fatec Jahu), Jaú, SP, Brasil \\ Departamento de Meio Ambiente e Recursos Hídricos. E-mail: jozrael.rezende@ fatec.sp.gov.br, \\ natalia.tecedor@fatec.sp.gov.br \\ *Autor correspondente
}

\section{RESUMO}

Este estudo avaliou a viabilidade do aproveitamento da água das chuvas no Tanque de Provas, utilizado em ensaios de modelos reduzidos de embarcações da Faculdade de Tecnologia de Jahu - Fatec Jahu, SP. O trabalho considerou os dados pluviométricos locais, a área de cobertura para captação e a demanda de água. Foi estimada a necessidade de água no processo de limpeza por filtragem, lavagem e evaporação do Tanque de Provas. O dimensionamento do reservatório foi calculado conforme as metodologias descritas na NBR 15527, que determina os requisitos para o aproveitamento de coberturas em áreas urbanas para fins não potáveis. $\mathrm{O}$ volume do reservatório selecionado como a melhor alternativa após as análises comparativas considerou as restrições locais e o risco de não atendimento, permitiu o máximo aproveitamento da água pluvial e resultou na maior redução possível da demanda de água potável do sistema de abastecimento público.

Palavras-chave: captação de água pluvial, não potável, índice pluviométrico.

\section{Use of rooftop rainwater of buildings: reservoir volume estimation by methods described in the NBR 15527}

\begin{abstract}
This paper explores the possibility of harvesting rainwater in a Testing Tank used to test scale models of boats and ships in Jahu College of Technology, São Paulo State. We considered local rainfall data, the coverage area for catchment and the demand for water. Water demand was estimated for cleaning, filtering and evaporation processes in the Testing Tank. The dimensions of the reservoir were calculated according to the methodologies described in the NBR 15527, which prescribes the requirements for the use of roofs in urban areas for the catchment of rainwater for non-potable purposes. The volume of the reservoir selected enabled the best use of rainwater and resulted in a better reduction of water demand on the public supply system. It was chosen as the best alternative after comparative analysis considering the local restrictions and the risk of non-compliance.
\end{abstract}

Keywords: non-potable, precipitation index, rainwater harvesting. 


\section{INTRODUÇÃO}

Os recentes problemas de escassez de água enfrentados na região sudeste do país, em especial no estado de São Paulo, devidos às demandas cada vez maiores, a poluição dos mananciais e por vezes a gestão ineficiente dos sistemas de abastecimento público demonstram a necessidade do desenvolvimento de procedimentos destinados a promover o uso racional da água, privilegiando os usos mais nobres da água potável. Para fins não potáveis de usos urbanos e rurais da água, o aproveitamento de água de chuva é uma opção atrativa para minimizar os efeitos da falta de água.

Gomes et al. (2014) discutindo a temática de captação de água de chuva no Brasil avaliam que enquanto nas zonas rurais a água de chuva é utilizada para suprir as necessidades básicas, incluindo consumo humano, nas áreas urbanas à captação de água de chuva se destina as demandas secundárias, não potáveis, visando a economia da água potável distribuída por rede.

Os sistemas de aproveitamento das águas de chuva são classificados como medida não convencional de conservação de água. O aproveitamento das águas de chuva é praticado e pesquisado em diversos países tais como a Inglaterra, os Estados Unidos, a Alemanha, a Austrália e o Japão.

No Brasil existe um histórico de utilização destes sistemas na região nordeste e, desde a década passada, tem se discutido a sua utilização nas cidades do sudeste, como uma alternativa promissora para contribuir com a solução de dois grandes problemas urbanos: a escassez de água e as frequentes inundações nas zonas urbanas, principalmente nas regiões metropolitanas (Carvalho et al., 2007).

O uso destes sistemas além de proporcionar o aumento da oferta de água para as edificações reduzindo o consumo de água potável se apresenta como uma boa alternativa no combate às enchentes, funcionando como uma medida não estrutural no sistema de drenagem urbana. Existem, portanto, dois motivos para a utilização de água de chuva em áreas urbanas: a redução do consumo de água potável e a melhor distribuição da carga de águas pluviais imposta ao sistema de drenagem urbana. A principal desvantagem é a diminuição do volume de água coletado em períodos de estiagem (Calheiros et al., 2014).

A água de chuva captada pode ser utilizada no comércio e nas edificações residenciais para usos não potáveis, tais como descargas de bacias sanitárias, irrigação de jardins, lavagem de automóveis, lavagem de pisos, bem como em diversos processos industriais, e na composição do concreto na construção civil. Esta limitação deve-se à dificuldade de controle dos diversos fatores ambientais que levam a contaminação da água ao entrar em contato com as coberturas (May, 2004).

Os sistemas de aproveitamento das águas de chuva são formados basicamente pela área de captação, geralmente coberturas ou telhados; os componentes de transporte, calhas e condutores verticais; filtros e o reservatório. O dimensionamento do reservatório é o maior desafio para viabilizar o aproveitamento das águas pluviais, pois é, na maioria dos casos, o item mais caro do sistema (Bezerra et al., 2010; Cohim e Oliveira, 2009; Cohim et al., 2008; Mierzwa et al., 2007; May, 2004; Martinson e Thomas, 2009).

O dimensionamento adequado do reservatório de armazenamento é vital para garantir a viabilidade técnica e econômica de um sistema de aproveitamento de água de chuva. No processo busca-se determinar a capacidade volumétrica capaz de atender a maior demanda possível com o menor custo, pois reservatórios demasiadamente grandes podem ser inviáveis tanto física quanto economicamente. O reservatório de um sistema de aproveitamento de água de chuva não deve permanecer ocioso por longo período, bem como não pode provocar o desperdício de água pluvial em detrimento ao atendimento da demanda necessária.

Devem ser consideradas as características climáticas da região, principalmente no que diz respeito às variações pluviométricas, as demandas para cada um dos usos previstos para as 
águas das chuvas; e também o tipo de superfície de captação, podendo ser recomendado inclusive algum tipo de tratamento, dependendo da qualidade exigida ao uso pretendido. Com isso, demonstra-se a importância do descarte da primeira chuva na obtenção de água de melhor qualidade, fazendo com que a água captada seja mais limpa e a necessidade de seu tratamento subsequente seja reduzida ou até mesmo eliminada (Martinson e Thomas, 2009).

As variáveis de projeto podem levar a um determinado volume obtido no dimensionamento, permitindo utilizar esta água para atender à demanda local por alguns dias, alguns meses ou por todo o ano. Geralmente, os cálculos procuram garantir o atendimento de toda a demanda pelo maior período possível com o menor custo de implantação (Amorim e Pereira; 2008). Regiões com períodos secos longos são desfavoráveis ao armazenamento de água de chuva. Locais cujas precipitações apresentam maior consistência ao longo do ano permitem melhores resultados hidráulicos e econômicos (Chaib et al., 2015).

Fewkes (2015) avaliando o desempenho de sistemas de captação de água de chuva em Nothingham, Inglaterra, utilizou como dados de entrada: séries históricas de precipitação diária, a relação área do telhado e demanda, e o período de armazenamento, para avaliar a eficiência de uso de águas pluviais nos usos residenciais não potáveis.

A Norma Brasileira NBR 15527 (ABNT, 2007) que fornece os requisitos para o aproveitamento de água de chuva da cobertura em áreas urbanas para fins não potáveis, além de especificar uma série de características dos reservatórios tais como extravasor, dispositivo de esgotamento, cobertura, inspeção, ventilação, segurança e minimização do turbilhonamento descreve seis métodos de cálculo para o dimensionamento dos reservatórios: Rippl, Simulação, Azevedo Neto, prático alemão, prático inglês e prático australiano. Este trabalho teve como objetivo calcular a dimensão do reservatório de um sistema de captação de água das chuvas captadas na cobertura de um prédio, onde está localizado o Tanque de Provas e Ensaios de modelos reduzidos de embarcações da Fatec Jahu; visando sua utilização nos processos de limpeza por filtragem, lavagem e evaporação do mesmo.

O processo de limpeza da água por filtragem e lavagem e a evaporação no tanque levam a necessidade constante de reposição de água. A água utilizada para reposição do volume perdido atualmente nestes processos é fornecida pelo serviço de água do município, ou seja, é água potável.

O trabalho analisa a viabilidade de captação das águas das chuvas da cobertura do prédio do Estaleiro Escola para este fim, considerando que a água utilizada no tanque de provas não precisa ser potável. Em um cenário de escassez hídrica é fundamental contribuir para a manutenção de níveis adequados de abastecimento de água potável, além disso, a captação de água de chuva de cobertura de prédios públicos implica em menor demanda de água tarifada, ou seja, reduz custos.

\section{MATERIAL E MÉTODOS}

A Faculdade de Tecnologia de Jahu - Fatec Jahu é uma unidade de ensino superior pública do Estado de São Paulo. São sessenta e cinco as Faculdades de Tecnologia no estado, vinculadas ao Centro Estadual de Educação Tecnológica Paula Souza, autarquia subordinada à Secretaria de Desenvolvimento Econômico, Ciência e Tecnologia. A Fatec Jahu, criada em 1990, oferece oito cursos de graduação tecnológica, dos quais dois são da área naval: Construção Naval e Sistemas Navais. Seu campus está instalado na Rua Frei Galvão sem número no Jardim Pedro Ometto e ocupa uma área de $67.761,91 \mathrm{~m}^{2}$. Atualmente a unidade tem aproximadamente 1.700 alunos, 90 docentes e 40 funcionários.

O Tanque de Provas da Fatec Jahu está localizado em um prédio com 1.063,69 $\mathrm{m}^{2}$ de área construída. Ele funciona como um dos laboratórios destinados aos Cursos Superiores de 
Tecnologia em Construção Naval e Sistemas Navais, denominado "Estaleiro Escola". O Tanque de Provas é utilizado para a realização de testes e ensaios com modelos reduzidos de embarcações. Sua principal função é avaliar o comportamento hidrodinâmico dos cascos e das estruturas de uma embarcação. O tanque de provas da Fatec Jahu possui $33 \mathrm{~m}$ de comprimento, $3 \mathrm{~m}$ de largura e 1,8 $\mathrm{m}$ de altura e é operado com lâmina d'água de 1,5 m, ou seja, armazena um volume de aproximadamente 148,5 $\mathrm{m}^{3}$ de água. Na Figura 1 está apresentada a localização da Faculdade de Tecnologia de Jahu - Fatec Jahu, do Estaleiro Escola e do tanque de provas.

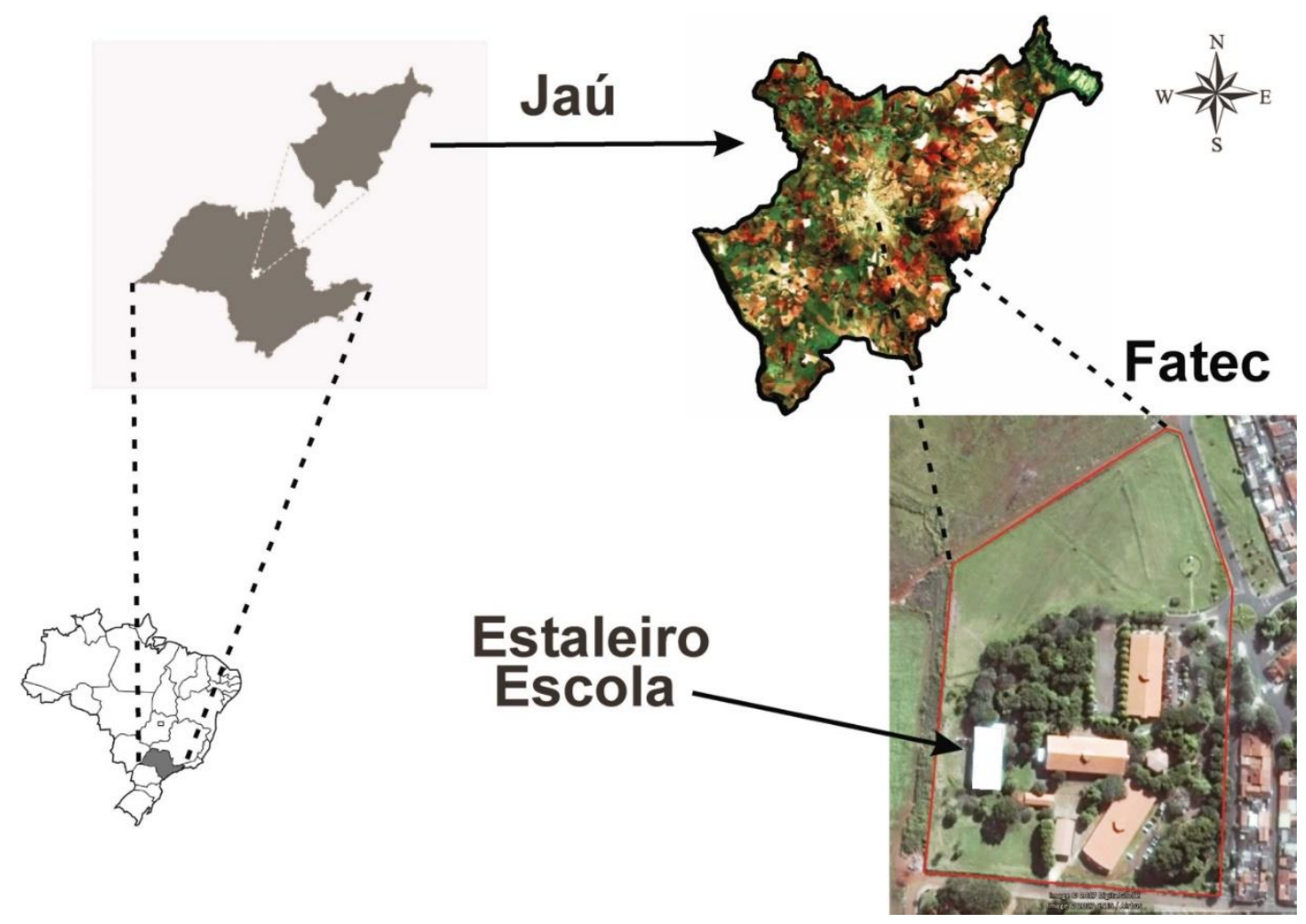

Figura 1. Localização da Fatec Jahu, do Estaleiro Escola e do tanque de provas.

Para verificar a viabilidade de economia de água potável, por meio da substituição por água de chuva para fins não potáveis nos processos de filtragem e lavagem e evaporação do tanque de provas, a metodologia foi organizada com as seguintes etapas:

a) Levantamento e análise de série histórica de chuvas diárias;

b) Definição do coeficiente de escoamento da cobertura, da demanda de água e do percentual da demanda de água a ser substituída por água pluvial;

c) Determinação do volume consumido nos processos de filtragem, lavagem e evaporação do tanque de provas;

d) Dimensionamento do reservatório de água de chuva pelos 6 métodos descritos na NBR ABNT 15527;

e) A simulação de sistemas de captação de águas pluviais, utilizando o programa computacional "Netuno 4" (Ghisi e Cordova, 2014), estabelecendo-se 20.000 L como volume máximo, tendo em vista as necessidades e as condições locais do estudo de caso;

f) Determinação do volume ideal do reservatório considerando o percentual de dias do ano em que a demanda de água pluvial é atendida utilizando "Netuno 4", tomando-se por base a Equação 1. 


$$
V=P / 1000 \times A \times C
$$

em que:

$V$ é o volume captado em $\mathrm{m}^{3} \cdot \mathrm{dia}^{-1}$;

$P$ é a precipitação em mm.dia ${ }^{-1}$ (base de dados de 5 anos);

$A$ é a área de coleta de água em $\mathrm{m}^{2}$;

Cé o coeficiente de escoamento da cobertura.

\subsection{Regime pluviométrico em Jaú}

O clima no município de Jaú é do tipo Aw", tropical chuvoso com inverno seco e mês mais frio com temperatura média superior a $18^{\circ} \mathrm{C}$. O mês mais seco, agosto, tem precipitação média inferior a $30 \mathrm{~mm}$. (CEPAGRI, 2013).

Análise da precipitação média anual e mensal da Bacia Hidrográfica do Rio Jaú, utilizando uma série histórica de 15 anos entre 1984 e 1998, de 2 postos pluviométricos (D5-008 e D5-084), ambos pertencentes à rede do Departamento de Águas e Energia Elétrica do Estado de São Paulo - DAEE resultou em 1418,8 mm. ano ${ }^{-1}$ de média; com 31,8 mm.mês ${ }^{-1}$ no trimestre mais seco, de junho a agosto; e 219,9 mm.mês ${ }^{-1}$ no trimestre mais chuvoso, de dezembro a fevereiro (Rezende et al., 2011).

Obregón et al. (2014) estudando as possíveis alterações nos padrões de chuva no Estado de São Paulo, decorrentes das mudanças climáticas, obtiveram resultados que indicaram um aumento da frequência e da intensidade de chuvas extremas na região central do estado nas próximas décadas. As projeções também sugerem um aumento significativo na frequência de veranicos nessa mesma região, indicando que as chuvas extremas serão concentradas em alguns dias e ocorrerão entre períodos de seca mais longos.

Desta forma, este estudo, optou por utilizar dados mais atuais de precipitação, utilizando para o cálculo do dimensionamento do reservatório a série histórica de chuvas diárias de 5 anos, entre janeiro de 2011 e dezembro de 2015, por ser o intervalo disponível e consistido, registrado na Estação Hidrometeorológica Ibica-re-ig, localizada no campus da Fatec Jahu, a 200 metros de distância do estaleiro escola. Muito embora os valores de precipitação média anuais e mensais entre 2011 e 2015 sejam próximos aos da análise realizada por Rezende et al. (2011), foi observada maior concentração da precipitação, implicando em menor número de dias com chuva e maiores intervalos sem chuvas ou com precipitação inferior a $2 \mathrm{~mm} \cdot \mathrm{dia}^{-1}$ nesta década.

As Figuras 2a e $2 b$ apresentam as precipitações anuais e médias mensais registradas no período de janeiro de 2011 a dezembro de 2015.

As Figuras $3 \mathrm{a}$ e $3 \mathrm{~b}$ apresentam a precipitação diária em mm.dia ${ }^{-1}$ e o número de dias consecutivos sem precipitação ou com precipitação inferior a $2 \mathrm{~mm} \cdot \mathrm{dia}^{-1}$, valor adotado como necessário para limpeza da cobertura, ou seja, valor do escoamento inicial considerado como descarte devido a contaminação decorrente de resíduos depositados na cobertura, conforme ABNT (2007). O menor intervalo no período foi observado no mês de março, com 6 dias sem chuvas ou com precipitação inferior a $2 \mathrm{~mm} \cdot \mathrm{dia}^{-1}$, o maior intervalo médio aconteceu no mês de agosto com 23 dias consecutivos em média sem precipitação ou com precipitação inferior a $2 \mathrm{~mm} \cdot \mathrm{dia}^{-1}$. 


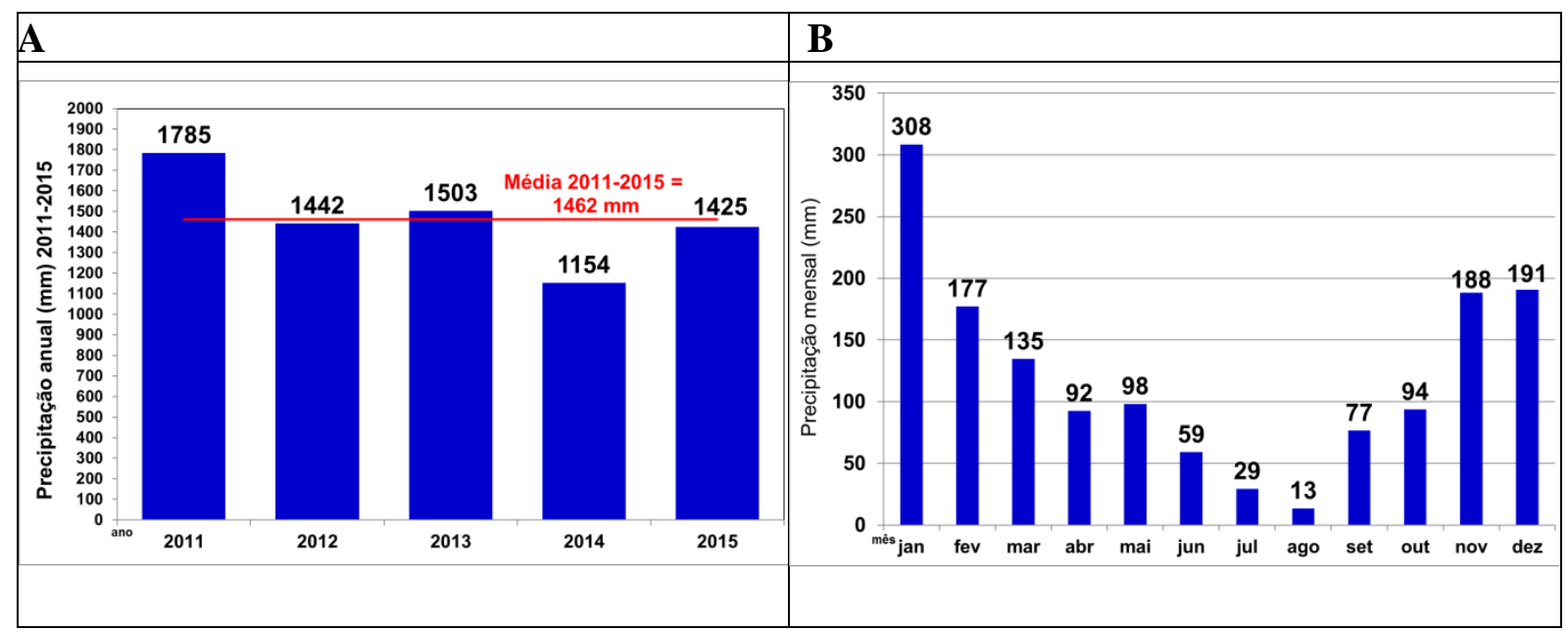

Figura 2. A) Precipitação anual; B) Médias mensais, registradas na Estação Hidrometeorológica Ibica-re-ig/Fatec Jahu no período 2011-2015.

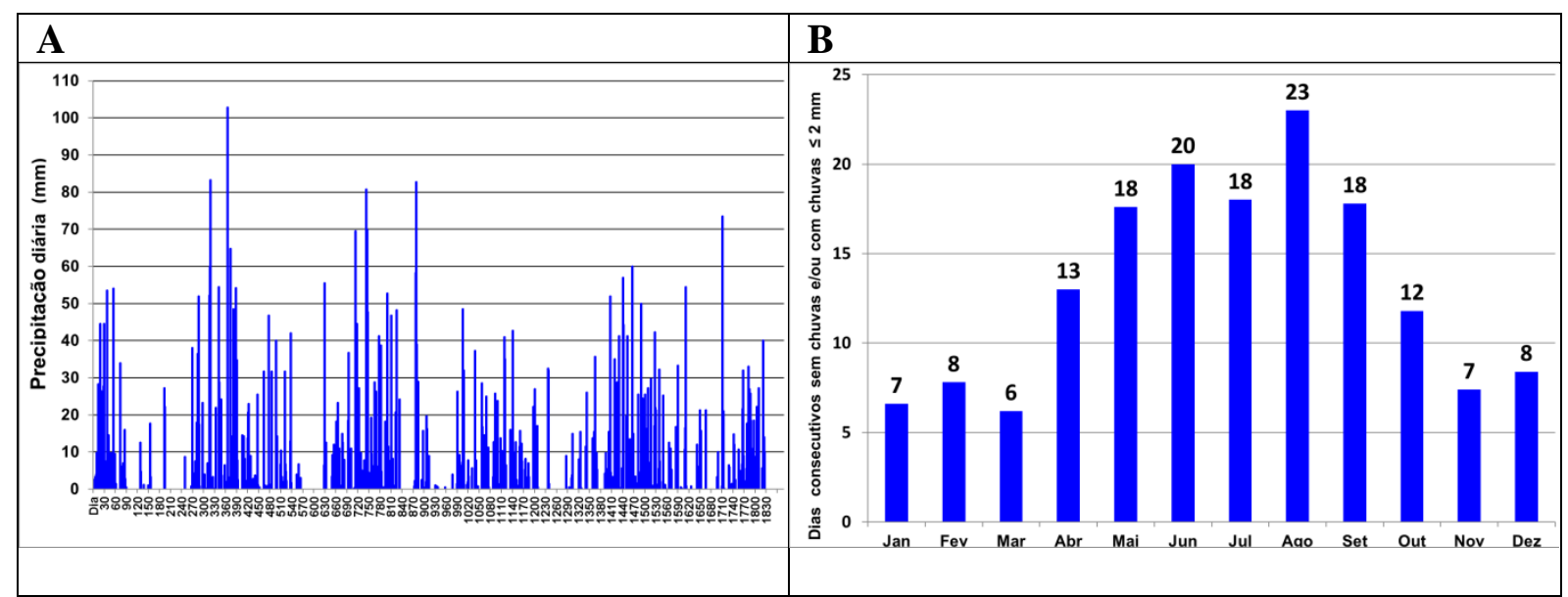

Figura 3. A) Precipitação diária registrada na Fatec Jahu no período 2011-2015; B) número de dias consecutivos sem precipitação ou com precipitação inferior a $2 \mathrm{~mm} \cdot \operatorname{dia}^{-1}$.

\subsection{Métodos de dimensionamento de reservatório descritos na NBR 15527}

A Norma Brasileira NBR 15527 (ABNT, 2007) descreve seis métodos de cálculo para o dimensionamento dos reservatórios: Rippl, Simulação, Azevedo Neto, prático alemão, prático inglês e prático australiano.

\subsubsection{Método de Rippl}

O método de Rippl, também chamado de diagrama de massa, é o procedimento mais comumente utilizado para dimensionar reservatórios em sistemas de aproveitamento de água de chuva. Geralmente ele apresenta o valor de referência máxima do volume do reservatório. Geralmente se utiliza uma série histórica de precipitações mensais a mais extensa possível, muito embora possam ser usadas séries de chuvas diárias (Tomaz, 2011). O dimensionamento é realizado conforme as Equações 2 e 3.

$$
S_{(t)}=D_{(t)}-Q_{(t)}
$$

em que:

$S_{(t)}$ é o volume de água no reservatório do tempo t; 
$V=\sum S_{(t)}$ somente para valores $S_{(t)}>0 ;$

$D_{(t)}$ é a demanda ou consumo no tempo t;

$Q_{(t)}$ é o volume de água aproveitável no tempo t.

$Q_{(t)}=C \times P_{(t)} \times A$

em que:

$C$ é o coeficiente de escoamento superficial;

$P_{(t)}$ é a precipitação no tempo $t$;

$A$ é a área de captação;

Vé o volume do reservatório.

\subsubsection{Método da Simulação}

Nesse método, os registros de precipitação (mensais ou diários) são utilizados para simular o comportamento do volume de água no reservatório. O volume do reservatório é definido de acordo com a demanda e aplica-se a equação da continuidade de um reservatório finito, conforme a Equações 3 e 4 .

$$
S_{(t)}=Q_{(t)}+S_{(t-1)}-D_{(t)}
$$

em que:

$S_{(t)}$ é o volume de água no reservatório do tempo t;

$S_{(t-1)}$ é o volume de água no reservatório do tempo t-1;

$Q_{(t)}$ é o volume de água no tempo t (Equação 3); sendo que: $0 \leq S_{(t)} \leq V$;

$D_{(t)}$ é a demanda ou consumo no tempo t.

\subsubsection{Método Azevedo Neto}

O volume de chuva é obtido pela Equação 5.

$V=0,042 \times P \times A \times T$

em que:

Pé o valor numérico da precipitação média anual expresso em milímetros (mm);

Té o valor numérico dos meses de pouca chuva ou de seca;

$A$ é o valor numérico da área de coleta em projeção, expresso em metros quadrados $\left(\mathrm{m}^{2}\right)$;

$V$ é o valor numérico do volume de água aproveitável e o volume de água do reservatório, expresso em (L).

\subsubsection{Método prático alemão}

Método empírico onde se toma o menor valor volume do reservatório que corresponde ao menor valor entre $6 \%$ do volume anual de precipitado aproveitável ou $6 \%$ do volume anual de consumo conforme a Equação 6.

$$
V_{\text {adotado }}=\min (V ; D) \times 0,06
$$


em que:

$V_{\text {adotado }}$ é o valor numérico do volume de água do reservatório, expresso em litros (L); (L);

$V$ é o valor numérico do volume aproveitável de água de chuva anual, expresso em litros

$D$ é o valor numérico da demanda anual de água não potável, expresso em litros (L).

\subsubsection{Método prático inglês}

O volume de chuva é obtido pela Equação 7.

$$
V=0,05 \times P \times A
$$

em que:

Pé o valor numérico da precipitação média anual expresso em milímetros (mm);

$A$ é o valor numérico da área de coleta em projeção, expresso em metros quadrados $\left(\mathrm{m}^{2}\right)$;

$V$ é o valor numérico do volume de água aproveitável e o volume de água do reservatório, expresso em (L).

\subsubsection{Método prático australiano}

O volume de chuva é obtido pela Equações 8,9 e 10. O cálculo do volume do reservatório é realizado por tentativas, até que sejam verificados valores otimizados. Para o primeiro mês considera-se o reservatório vazio.

$$
Q=A \times C \times(P-I)
$$

em que:

$Q$ é o volume mensal produzido pela chuva;

$A$ é a área de coleta;

$C$ é o coeficiente de escoamento superficial, geralmente 0,80 ;

$P$ é a precipitação média mensal; $2 \mathrm{~mm}$.

I é a interceptação da água que molha as superfícies e perdas por evaporação, geralmente

$$
V_{(t)}=V_{(t-1)}+Q_{(t)}-D_{(t)}
$$

em que:

$V_{(t)}$ é o volume de água que está no tanque no fim do mês t;

$V_{(t-1)}$ é o volume de água que está no tanque no início do mês t;

$Q_{(t)}$ é o volume mensal produzido pela chuva no mês t;

$D_{(t)}$ é a demanda mensal.

Quando $\left(V_{(t-1)}+Q_{(t)}-D_{(t)}\right)<0$, então $V_{(t)}=0$.

$$
P_{(t)}=N_{(t)}{ }_{N}
$$


em que:

$P_{(t)}$ é a falha;

$N_{(t)}$ é o número de meses em que o reservatório não atendeu a demanda, isto é quando $V_{(t)}=0$;

$N$ é o número de meses considerado, geralmente 12 meses.

Confiança $-\left(1-P_{(t)}\right)$ Recomenda-se que os valores de confiança estejam entre $90 e$ $99 \%$.

\subsection{Coeficiente de escoamento da cobertura, demanda de água, percentual de substituição por água pluvial e volume ideal do reservatório}

Para a estimativa do consumo de água no tanque de provas foram utilizados os parâmetros apresentados por Tomaz (2000), para a manutenção e evaporação de piscinas. Segundo o autor o uso de água utilizado na limpeza e filtragem de piscinas é de $3 \mathrm{~L} \cdot \mathrm{dia}^{-1} \cdot \mathrm{m}^{-2}$, considerando-se 8 manutenções por mês. Como as atividades de limpeza e filtragem no tanque de provas da Fatec Jahu acontecem com menor frequência, foi considerado o valor de 1,6 L.dia ${ }^{-1} \cdot \mathrm{m}^{-2}$, para uma frequência semanal. As perdas por evaporação em piscinas variam de 2,5 a $5,75 \mathrm{~L} \cdot \mathrm{dia}^{-1} \cdot \mathrm{m}^{-2}$. Considerando que o tanque de provas se encontra abrigado no Estaleiro Escola, o valor de evaporação utilizado foi o limite inferior do parâmetro.

A necessidade de reposição de água devida ao processo de limpeza da água por filtragem e lavagem e por evaporação estimada é, portanto de $4,1 \mathrm{~L} \cdot \mathrm{dia}^{-1} \cdot \mathrm{m}^{-2}$. Considerando que o tanque de provas tem $33 \mathrm{~m}$ de comprimento e $3 \mathrm{~m}$ de largura, ou seja, $99 \mathrm{~m}^{2}$ de área, a demanda pode ser estimada em $406 \mathrm{~L} \cdot \mathrm{dia}^{-1}$, ou 12,35 $\mathrm{m}^{3} \cdot \mathrm{mês}^{-1}$.

A cobertura do Estaleiro Escola é de telhas metálicas, de chapo de aço, tipo sanduíche, também chamadas de telhas termoacústicas. Hofkes (1981) e Fraiser (1975) apud May (2004) definiram valores de coeficiente de escoamento ou coeficiente de Runoff para telas metálicas variando de 0,7 a 0,9 tendo em vista as perdas por evaporação, vazamentos e outras. $O$ trabalho utilizou o valor de 0,8 para o coeficiente de escoamento, ou seja, $80 \%$ de aproveitamento do total precipitado sobre a cobertura. O percentual da demanda total de água potável a ser substituída por água pluvial foi definido como $100 \%$.

A determinação do volume ideal do reservatório foi realizada por meio do programa computacional para simulação de sistemas de captação de águas pluviais "Netuno 4". No programa o volume ideal do reservatório é definido como o maior percentual de utilização de água pluvial (Equação 11), que é a relação entre o potencial de economia de água potável por meio do aproveitamento da água pluvial e a demanda total de água que pode ser suprida por água pluvial. (Ghisi e Cordova, 2014).

$$
P_{\text {pluv }}=E_{\text {pot }} / P_{\text {subst }}
$$

em que:

$P_{\text {pluv }}$ é o percentual de utilização de água pluvial, em \%;

$E_{p o t}$ é o potencial de economia de água potável por meio do aproveitamento da água pluvial, em \%; em $\%$.

e $P_{\text {subst }}$ é o percentual da demanda total de água que pode ser suprida por água pluvial, 


\section{RESULTADOS E DISCUSSÃO}

Considerando a área de cobertura do telhado que é de $1.063,69 \mathrm{~m}^{2}$, o descarte do

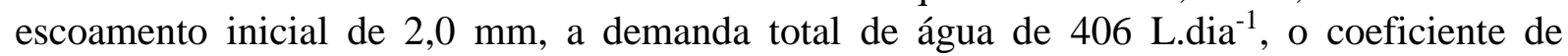
escoamento superficial de 0,8 e o percentual ideal de $100 \%$ de substituição da demanda total por água pluvial, foram feitos os cálculos para o dimensionamento dos reservatórios de acordo com os seis métodos do Anexo A da NBR 15527 (ABNT, 2007) descritos no item 2.2. A Tabela 1 apresenta o volume do reservatório para armazenamento da água de chuva, calculado de acordo com cada um dos métodos.

Tabela 1. Volume dos reservatórios para captação da água de chuva precipitada na cobertura do Estaleiro Escola/Fatec Jahu de acordo com os métodos descritos no Anexo da NBR 15527.

\begin{tabular}{lc}
\hline Método & Reservatório $\left(\mathrm{m}^{3}\right)$ \\
\hline 2.1 de Rippl & 13,64 \\
2.2 da simulação & 5,00 \\
2.3 Azevedo Neto & 130,63 \\
2.4 prático alemão & 8,89 \\
2.5 prático inglês & 77,76 \\
2.6 prático australiano & 665,79 \\
\hline
\end{tabular}

Os métodos para dimensionamento de reservatórios de água de chuva "Azevedo Neto" e "prático Inglês" não consideram a demanda de água e isso foi determinante para o superdimensionamento do reservatório, que foi respectivamente de $130.600 \mathrm{~L}$ e $77.760 \mathrm{~L}$. O método "prático australiano", considera a demanda, porém tendo em vista o tamanho da área de cobertura, o volume obtido foi ainda maior. A capacidade do reservatório para este método foi estimada em $665.790 \mathrm{~L}$. Considerando que para viabilizar o aproveitamento de águas pluviais um dos maiores desafios é a definição do volume do reservatório (Mierzwa et al., 2007), os resultados obtidos por estes três métodos foram considerados incompatíveis com as necessidades e condições locais do estudo de caso e foram descartados como alternativas.

Os métodos "de Rippl”, "da simulação" e "prático alemão" resultaram em valores viáveis para a capacidade do reservatório. Os valores obtidos foram respectivamente de $13.640 \mathrm{~L}$, 5.000 L e 8.890 L. Para simular os cenários dos sistemas de captação de água de chuvas do estudo de caso, os valores obtidos por estes três métodos foram inseridos no programa computacional Netuno 4 (Ghisi e Cordova, 2014) juntamente com as variáveis fixas área de cobertura do telhado, o descarte do escoamento inicial, demanda total de água, coeficiente de escoamento superficial e percentual de substituição da demanda total por água pluvial. $\mathrm{Na}$ Tabela 2 estão sintetizados os resultados da simulação, considerando os volumes de reservatórios calculados.

Tabela 2. Cenários dos sistemas de captação de águas pluviais para reservatórios de volumes conhecidos simulados pelo programa computacional Netuno 4 .

\begin{tabular}{lccc}
\hline Método & 2.1 de Rippl & 2.2 da simulação & 2.4 prático alemão \\
\hline Reservatório $\left(\mathrm{m}^{3}\right)$ & 13,64 & 5,00 & 8,89 \\
\hline Potencial de utilização de água pluvial $(\%)$ & 93,26 & 77,89 & 87,15 \\
Volume consumido água pluvial $\left(\mathrm{m}^{3}\right)$ & 138,20 & 115,42 & 129,15 \\
Volume consumido água potável $\left(\mathrm{m}^{3}\right)$ & 9,99 & 32,77 & 19,04 \\
Volume extravasado $\left(\mathrm{m}^{3}\right)$ & $1.092,13$ & $1.098,53$ & $1.094,25$ \\
Atendimento completo $(\%)$ & 93,04 & 77,50 & 86,63 \\
Atendimento parcial $(\%)$ & 0,49 & 1,74 & 0,76 \\
Sem atendimento $(\%)$ & 6,47 & 20,76 & 12,61 \\
Mês crítico; \% de atendimento & agosto; 62,58 & agosto; 23,23 & agosto; 40,00 \\
\hline
\end{tabular}


Os melhores resultados da simulação foram obtidos pelo método "de Rippl”. Os resultados demonstraram que, o reservatório dimensionado por esse método permitiria uma economia de água potável de $93,26 \%$. Isto representa $93,04 \%$ dos dias do ano com atendimento completo e apenas $6,47 \%$ sem atendimento. No mês de agosto, o mais crítico do ano, que teve em média nos últimos 5 anos, 23 dias consecutivos sem precipitação ou com precipitação inferior a $2 \mathrm{~mm} \cdot \mathrm{dia}^{-1}$, o atendimento chega a $62,58 \%$.

Ao ser aplicada a simulação para reservatórios com diversos volumes, considerando o volume máximo de $20.000 \mathrm{~L}$, com o intervalo entre volumes de $1.000 \mathrm{~L}$ e assinalando a opção "indicar volume ideal para o reservatório inferior" foram obtidos como resultados um gráfico de potencial de economia de água potável por meio do uso de água pluvial em função dos diversos volumes do reservatório inferior, com a determinação do volume ideal do reservatório (Figura 4); e os gráficos de consumo de água pluvial e atendimento da demanda de água pluvial (Figura 5) e volume extravasado (Figura 6).

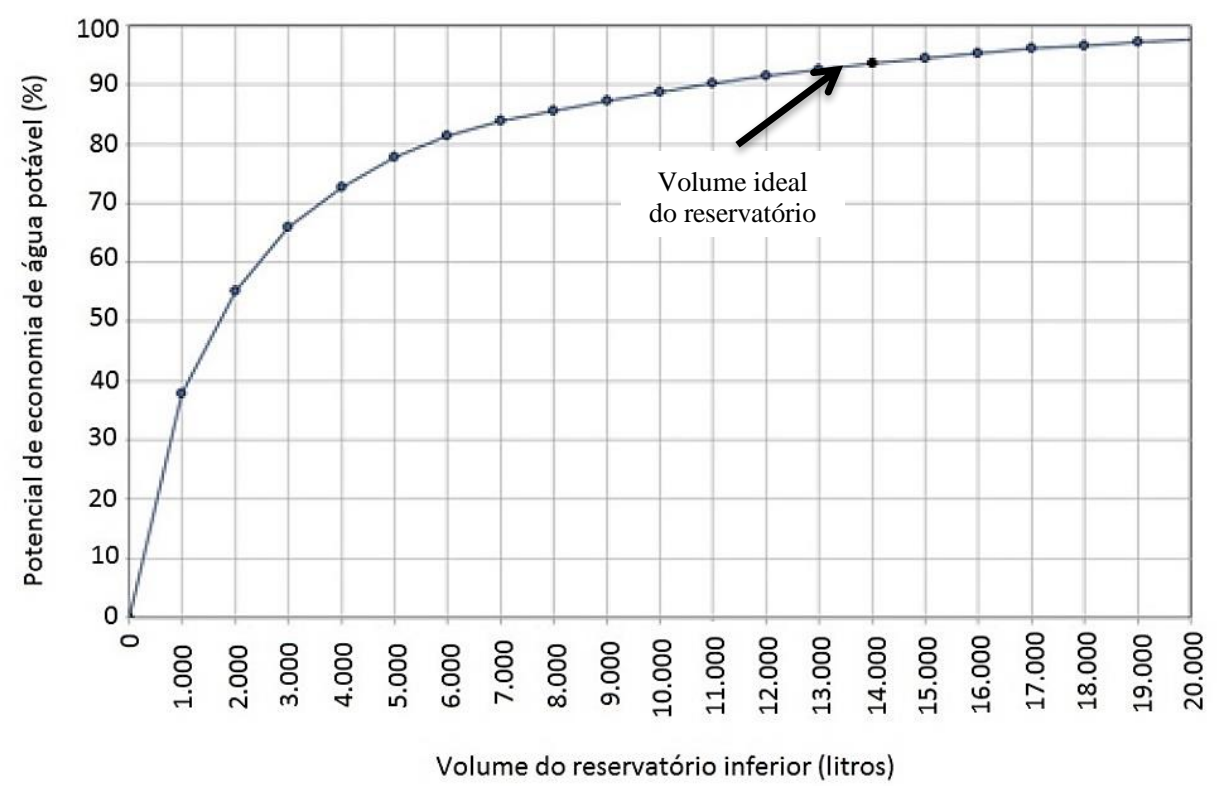

Figura 4. Potencial de economia de água potável (\%) por meio do uso de água pluvial em relação ao volume do reservatório inferior $(\mathrm{L})$ e volume ideal do reservatório $(\mathrm{L})$.

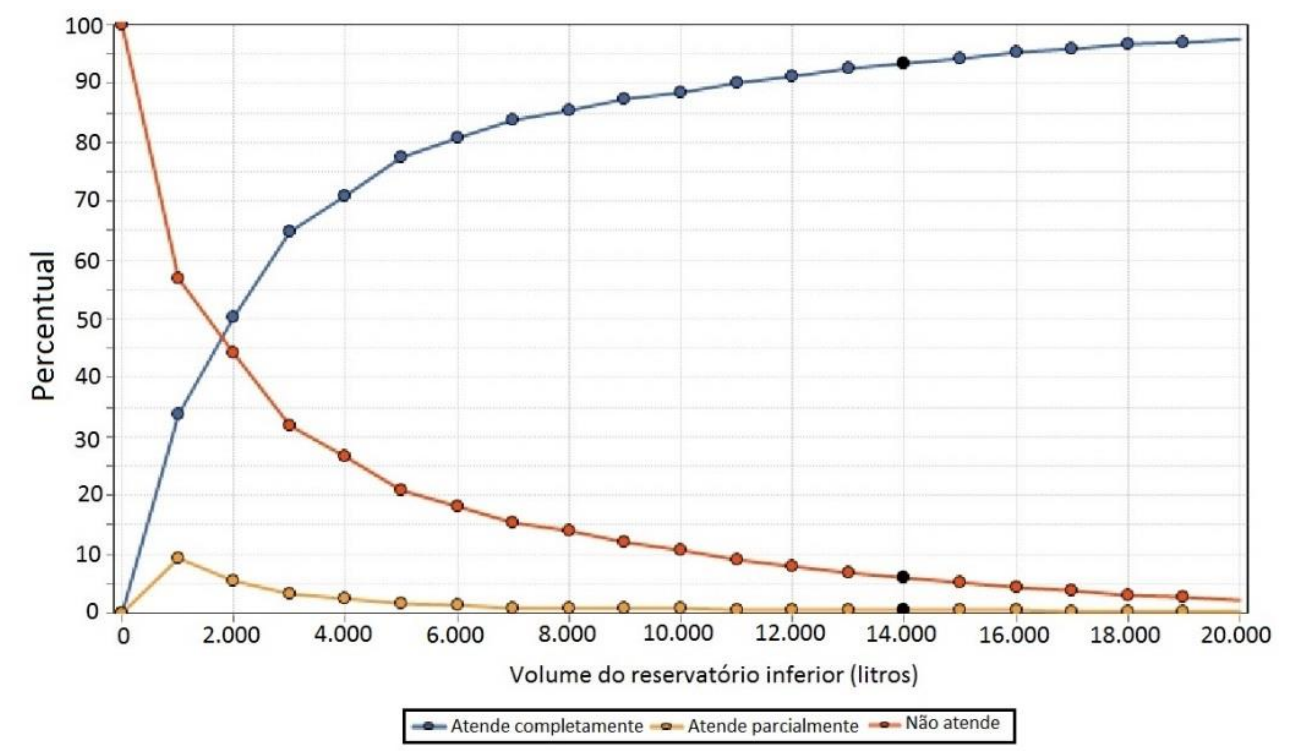

Figura 5. Atendimento da demanda (\%) em relação ao volume do reservatório (L). 


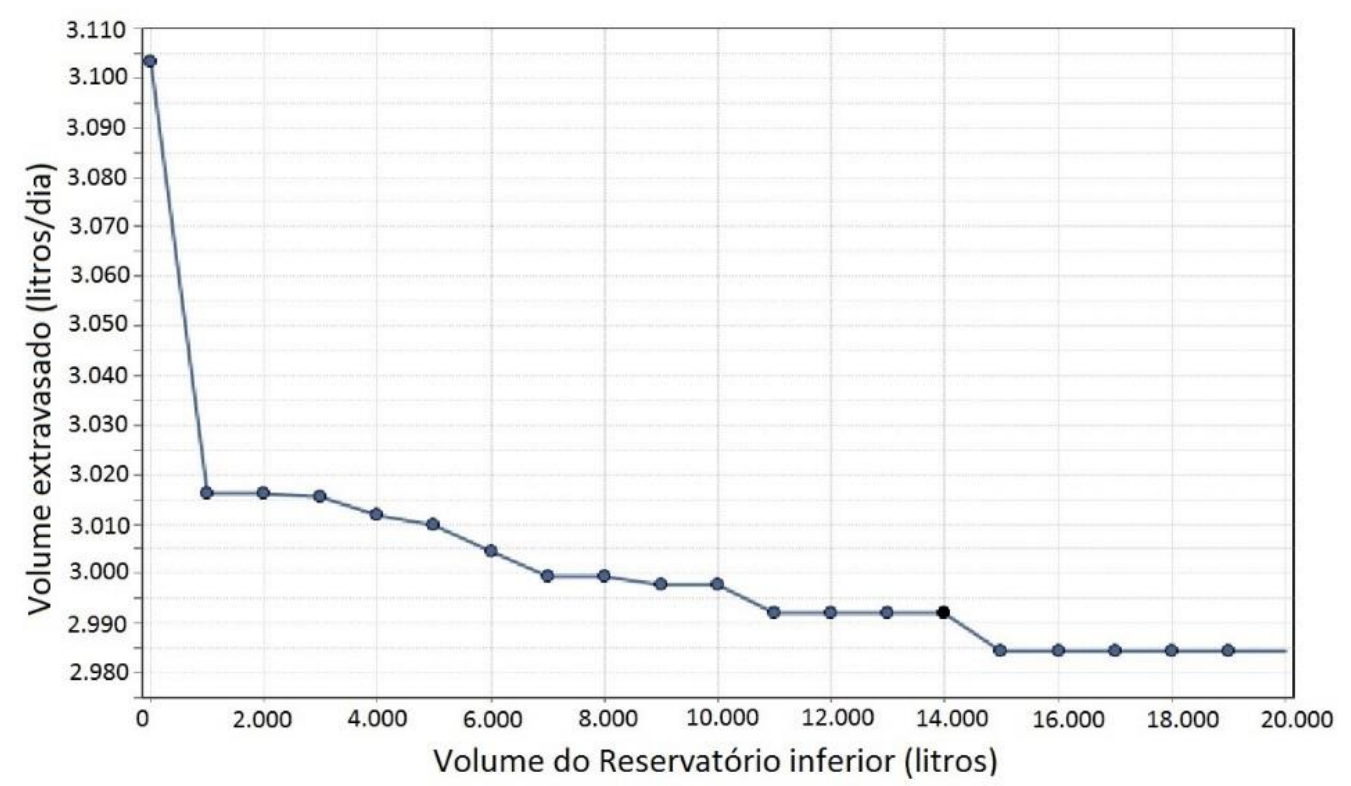

Figura 6. Volume extravasado de água pluvial $\left({\left.\mathrm{L} \cdot d i a^{-1}\right)}^{-1}\right.$ em relação ao volume do reservatório $(\mathrm{L})$.

O volume ideal estimado pela simulação para reservatórios com diversos volumes foi de 14.000 L, valor muito próximo ao calculado pelo método "de Rippl” (13.640 L). O percentual de atendimento pleno da demanda para este volume de reservatório foi de 93,60\% e o volume extravasado foi de $2.995 \mathrm{~L} . d i a^{-1}$.

A partir dos resultados expostos e considerando-se a convergência destes resultados com os valores obtidos pelo método "de Rippl", optou-se por escolher o volume do reservatório obtido neste método como o volume ótimo deste estudo de caso. Considerando as capacidades dos reservatórios a partir de $5.000 \mathrm{~L}$ encontrados no mercado da construção civil: $5.000 \mathrm{~L}$; 7.500 L; $10.000 \mathrm{~L} ; 15.000 \mathrm{~L}$ e $20.000 \mathrm{~L}$; e objetivando-se a aplicação prática dos resultados, pode-se considerar que o reservatório ideal para o máximo aproveitamento de água de chuva para o cenário analisado deve ter $15.000 \mathrm{~L}$ de capacidade.

\section{CONCLUSÃO}

Alguns métodos de dimensionamento de reservatório para armazenamento de água de chuva descritos no anexo da NBR 15527 resultaram em reservatórios incompatíveis com as condições do objeto de estudo (Azevedo Neto, prático inglês e prático australiano). O melhor resultado foi obtido com o método de "Rippl". Embora o reservatório definido como ideal para este método pelo programa computacional "Netuno 4" não atenda a demanda total do volume de água potável consumido no processo de limpeza por filtragem, lavagem e evaporação do Tanque de Provas; a economia proporcionada por meio do uso de água pluvial e o percentual de atendimento da demanda justificam a implantação do sistema de aproveitamento de água das chuvas no Estaleiro Escola da Faculdade de Tecnologia de Jahu - Fatec Jahu. O aproveitamento da água pluvial apresenta-se como uma alternativa importante para a redução do consumo da água fornecida pelo sistema público de abastecimento.

O regime pluviométrico de Jaú/SP não é plenamente favorável ao aproveitamento de água de chuva tendo em vista a existência de um período seco de praticamente três meses (junho, julho e agosto). Pode-se deduzir que em outras regiões do estado de São Paulo, com regimes pluviométricos sem estação seca definida, podem ser obtidos resultados ainda melhores.

A metodologia aplicada ao estudo de caso mostrou-se apropriada para a determinação da capacidade ótima do reservatório para armazenamento de água de chuva. Considerando que o 
dimensionamento adequado do reservatório é o maior desafio para viabilizar técnica e economicamente o aproveitamento das águas pluviais, a continuidade do trabalho deve abordar a viabilidade econômica da opção escolhida.

É importante ressaltar a necessidade do aprofundamento dos estudos relativos à precipitação, a qualidade da água pluvial e aos demais equipamentos (filtros, calhas, tubulações e outros) necessários à implantação de um sistema de aproveitamento de água de chuva como o descrito neste trabalho.

\section{REFERÊNCIAS}

AMORIM, S. V.; PEREIRA, D. J. A. Estudo comparativo dos métodos de dimensionamento para reservatórios utilizados em aproveitamento de água pluvial. Ambiente Construído, v. 8, n. 2, p. 53-66, 2008.

ASSOCIAÇÃO BRASILEIRA DE NORMAS TÉCNICAS. NBR 15527: água de chuva: aproveitamento em áreas urbanas para fins não potáveis: requisitos. Rio de Janeiro, 2007.

BEZERRA, S. M. C.; CHRISTAN, P.; TEIXEIRA, C. A.; FARAHBAKHSH, K. Dimensionamento de reservatório para aproveitamento de água de chuva: comparação entre métodos da ABNT NBR 15527:2007 e Decreto Municipal 293/2006 de Curitiba, PR. Ambiente Construído, v. 10, n. 4, p. 219-231, 2010. http://dx.doi.org/10.1590/ S1678-86212010000400015

CALHEIROS, H. C.; GOMES, M. R.; ESTRELLA, P. M. A. Calidad de las aguas meteóricas em la ciudad de Itajubá, Minas Gerais, Brasil. Revista Ambiente \& Água, v. 9, n. 2, p. 336-346, 2014. http://dx.doi.org/10.4136/ambi-agua.1329

CARVALHO, G. S.; OLIVEIRA, S. C.; MORUZZI, R. B. Cálculo do volume do reservatório de sistemas de aproveitamento de água de chuva: Comparação entre métodos para aplicação em residência unifamiliar. In.: SIMPÓSIO NACIONAL DE SISTEMAS PREDIAIS: DESENVOLVIMENTO E INOVAÇÃO, 10., 2007, São Carlos. Anais... São Carlos: ANTAC, 2007.

CENTRO DE PESQUISAS METEOROLÓGICAS E CLIMÁTICAS APLICADAS À AGRICULTURA - CEPAGRI. Clima dos municípios paulista - a classificação climática de Köeppen para o estado de São Paulo. 2013. Disponível em: http://www.cpa.unicamp.br/outras-informacoes/clima_muni_289.html. Acesso em: 07 jul. 2017.

CHAIB, E. B.; RODRIGUES, F. C.; MAIA, B. H.; NASCIMENTO, N. O. Avaliação do potencial de redução do consumo de água potável por meio da implantação de sistemas de aproveitamento de água de chuva em edificações unifamiliares. Revista Brasileira de Recursos Hídricos, v. 20 n. 3, p. 605-614, 2015.

COHIM, E.; GARCIA, A.; KIPERSTOK, A. captação e aproveitamento de água de chuvas: dimensionamento de reservatórios. In: SIMPÓSIO DE RECURSOS HÍDRICOS DO NORDESTE, 9., 2008, Salvador. Anais... Salvador: ABRH, 2008.

COHIM, E.; OLIVEIRA, C. A Importância do intervalo de tempo na simulação do funcionamento de um reservatório de água de telhado. In: CONGRESSO BRASILEIRO DE ENGENHARIA SANITÁRIA E AMBIENTAL, 25, 2009, Recife. Anais... Recife, 2009. 
FEWKES, A. The verification of a behavioural model for simulating the hydraulic perfomance of rainwater harvesting systems. In: MEMON, F. A.; WARD, S. (Eds.). Alternative water supply systems. London: IWA, 2015. p. 47-61.

GHISI, E.; CORDOVA, M. M. Netuno 4. Florianópolis: Universidade Federal de Santa Catarina, Departamento de Engenharia Civil. 2014. Disponível em: http://labeee.ufsc.br/. Acesso em: 01 abr. 2016.

GOMES, U. A. F.; DOMÈNECH, L.; PENA, J. L.; HELLER, L.; PALMIER, L. R. A captação de água de chuva no Brasil: novos aportes a partir de um olhar internacional. Revista Brasileira de Recursos Hídricos, v. 19 n. 1, p. 7-16, 2014.

MARTINSON, D. B.; THOMAS, T. Quantifying the first-flush phenomenon: effects of firstflush on water yield and quality. In: INTERNATIONAL RAINWATER CATCHMENT SYSTEMS CONFERENCE, 14., 2009, Kuala Lumpur. Proceedings... Disponível em: https://goo.gl/zkkR2F. Acesso em: jul. 2017.

MAY, S. Estudo da viabilidade do aproveitamento de água de chuva para consumo não potável em edificações. 159 p. 2004. Dissertação (Mestrado em Engenharia de Construção Civil e Urbana) - Escola Politécnica, Universidade de São Paulo, São Paulo, 2004.

MIERZWA, J. C.; HESPANHOL, I.; DA SILVA, MD.; RODRIGUES, L. B. Águas Pluviais: método de cálculo do reservatório e conceitos para um aproveitamento adequado. Revista de Gestão de Águas da América Latina, v. 4, p. 29-37, 2007.

OBREGÓN, G. O.; MARENGO, J. A.; NOBRE, C. A. Rainfall and climate variability: longterm trends in the Metropolitan Area of São Paulo in the 20th century. Climate Research, v. 61, n. 2, p. 93-107, 2014. https://doi.org/10.3354/cr01241

REZENDE, J. H.; PIRES, J. S. R.; VENIZIANI JÚNIOR, J. C. T. Áreas prioritárias para Reserva Legal na Bacia Hidrográfica do Rio Jaú. Rio Claro - SP. Holos Environment, v. 11, n. 1, p. 16-30, 2011. http://dx.doi.org/10.14295/holos.v11i1.3443

TOMAZ, P. Aproveitamento de água de chuva: aproveitamento de água de chuva para áreas urbanas e fins não potáveis. 4. ed. São Paulo: Navegar, 2011. 208 p.

TOMAZ, P. Previsão de consumo de água: Interface das instalações prediais de água e esgoto com os serviços públicos. São Paulo: Navegar, 2000. 250 p. 